\title{
COMPARATIVE ANALYSIS OF A TRANSIENT HEAT FLOW AND THERMAL STRESSES BY ANALYTICAL AND NUMERICAL METHODS
}

\author{
G. ALMEIDA ${ }^{*}$, N. COELHO ${ }^{\dagger}$ AND N. ALKMIM* \\ * Grupo de Dinâmica e Fluido - Estrutura (GDFE) \\ Universidade de Brasília. \\ Departamento de Engenharia Civil e Ambiental \\ Campus Darcy Ribeiro, CEP 70919 - 900, Asa norte, Brasília-DF, Brasil \\ E-mail: gisele.vilela21@gmail.com \\ nasser.alkmim@gmail.com \\ ${ }^{\dagger}$ Universidade Federal do Vale do São Francisco - UNIVASF \\ Avenida Antonio Carlos Magalhães, 510 - Santo Antônio \\ CEP: 48902-300 - Juazeiro/BA \\ E-mail: naildea@yahoo.com.br
}

Key words: Coupled Problems, Finite Differences Method, Finite Elements Method, Heat Transfer, Thermomechanical Applications.

Abstract. The study of heat flow problems is of extreme importance in engineering, there is a need to know the temperatures imposed and generated, when appropriate, in the structural parts to be able to evaluate the stresses that can arise due to the thermal variations. These stresses arise due to imposed constraints, ie bodies can not move freely and consequently undesirable cracks may arise when the stresses are greater than the resistive capacity of the stressed parts. The analysis of these problems can be done in both analytical or numerical way, with the use of calculation methods, such as the Finite Difference Method (FDM) and the Finite Element Method (FEM), with aid of computational programs such as MATLAB, PYTHON and ANSYS, as used in this work. The results presented here show simple cases of transient thermal variation and thermomechanical coupling by two methods of analysis, aiming at the validation of the numerical methods and softwares used. The solutions were satisfactory, the temperatures and stresses were coincident for different methods, making possible to start studying more complex problems with confidence in the implemented code.

\section{INTRODUCTION}

Heat flow is a common phenomenon in engineering. The temperature variation may be responsible for problems in structural parts due to the appearance of thermal stresses that may exceed the design resistive capacity and, consequently, give rise to fissures.

The study of heat equations is necessary so that it is possible to analyze the behavior of the involved materials in any project. The imposed conditions, initial and boundary conditions have direct influence on the equation results.

One of the main objectives of heat conduction analysis is to know the temperature 
distribution, ie, how the temperature varies with the position in the domain. Conductive heat flow at any point in the middle or surface of a body can be determined by the Fourier law, represented by Partial Differential Equations (PDEs) [1].

Among the various mechanisms for solving heat transfer problems, there are the Finite Differences Method (FDM), easy to interpret and manipulate, the Finite Element Method (FEM), widely used in engineering, as well as the Analytical Methods, responsible for Mathematical solutions.

The MDF is a numerical procedure that solves PDEs by discretizing a continuous physical domain into a finite discrete mesh, approaching each partial derivative in the EDP by approximations of finite algebraic differences [2]. The finite difference equation must represent the exact solution of the PDE at each point of the discretized region in which the problem solution is to be obtained [3].

The FEM provides a general and systematic technique for the construction of base functions, which are necessary to model solutions of approximate boundary problems using, for example, the Galerkin method. According to [4], it is possible to construct approximate solutions for differential equations provided with a boundary condition, by dividing the domain of the solution into a finite number of subdomains.

Thermomechanical coupling is an alternative to problem solving using the methods mentioned. First, results of thermal analyzes are obtained. With the thermal distribution associated with the mechanical boundary conditions found, it is possible to find the stresses arising from the heat flux.

Therefore, this work intends to present analysis of heat flow and thermomechanical stresses for simple problems with the objective of accomplishing a preliminary and necessary step for studying the coupled problem in question. Thus, in this work will be presented comparisons between the Finite Element and the Finite Differences Methods for numerical solutions of the General Two-dimensional Heat Conduction Equation in Transient Regime and the coupled case of a plate submitted to a thermal variation.

\section{THEORETICAL FUNDAMENTS}

Analytical solutions to thermal problems, depending on the geometry and imposed initial and boundary conditions can be very complex or even impossible to determine. Numerical methods allow an easier and faster solution to these problems with the aid of computational tools. Therefore, in this work, the analytical methods, the FDM and the FEM were used, as will be presented in the sequence.

\subsection{General Heat Conduction Equation}

Heat conduction can be quantified in terms of differential equations. The mathematical model that describes the general heat conduction equation in rectangular coordinates, defined by $[1,2,3,4]$, is given by:

$$
k\left(\frac{\partial^{2} T}{\partial x^{2}}+\frac{\partial^{2} T}{\partial y^{2}}+\frac{\partial^{2} T}{\partial z^{2}}\right)+\dot{q}=\rho c \frac{\partial T}{\partial t}
$$

In which $\dot{\mathrm{q}}$ is the heat generation in respect to time $\left(\mathrm{W} / \mathrm{m}^{3}\right), \mathrm{k}$ is the termal conductivity 
$\left(\mathrm{W} / \mathrm{m}^{\circ} \mathrm{C}\right)$, c is the specific heat $\left(\mathrm{J} / \mathrm{g}^{\mathrm{o}} \mathrm{C}\right), \rho$ is specific mass $\left(\mathrm{Kg} / \mathrm{m}^{3}\right), \frac{\partial \mathrm{T}}{\partial \mathrm{t}}$ is the temperature variation in time, and $\left(\frac{\partial^{2} \mathrm{~T}}{\partial \mathrm{x}^{2}}+\frac{\partial^{2} \mathrm{~T}}{\partial \mathrm{y}^{2}}+\frac{\partial^{2} \mathrm{~T}}{\partial \mathrm{z}^{2}}\right)=\nabla^{2} \mathrm{~T}$ represents the termal gradient.

\subsection{General Heat Conduction Equation by Finite Differences Method (FDM):}

The FDM allows the temperature calculation at any point in the domain (Figure 1) from its boundary conditions.

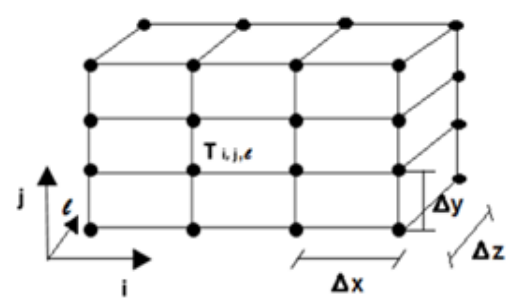

Figura 1: Finite Diferences Mesh Example.

(Coelho,2016)

The method consists in the substitution of differential equations by algebraic equations, making derivative transformations into finite differences. Based on studies carried out by $[8,5]$ the substitutions of First Order Differential Equations and Second Order Differential Equations are shown in table (1) by their respective Finite Differences forms:

Table 1: First and Second order derivatives expressions aproximated through the FDM.

\begin{tabular}{|c|c|c|c|c|}
\hline \multicolumn{2}{|c|}{$1^{\text {a }}$ Order of Derivatives: } & \multicolumn{3}{|c|}{$2^{\mathrm{a}}$ Order of Derivatives } \\
\hline$\partial \mathrm{T}$ & $\mathrm{T}_{\mathrm{i}+1}-\mathrm{T}_{\mathrm{i}-1} \quad \mathrm{~T}_{\mathrm{i}+1}-\mathrm{T}_{\mathrm{i}-1}$ & $\partial^{2} \mathrm{~T}$ & $\mathrm{~T}_{\mathrm{i}+1, \mathrm{j}, 1}-2 \mathrm{~T}_{\mathrm{i}, \mathrm{j}, 1}+\mathrm{T}_{\mathrm{i}-1, \mathrm{j}, 1}$ & $\mathrm{~T}_{\mathrm{i}+1, \mathrm{j}, 1}-2 \mathrm{~T}_{\mathrm{i}, \mathrm{j}, 1}+\mathrm{T}_{\mathrm{i}-1, \mathrm{j}, 1}$ \\
\hline$\overline{\partial x}$ & $\overline{x_{i+1}-x_{i-1}}$ & $\overline{\partial x^{2}}$ & $\left(x_{i+1}-x_{i-1}\right)^{2}$ & $\Delta \mathrm{x}^{2}$ \\
\hline$\partial \mathrm{T}$ & $T_{j+1}-T_{j-1}=T_{j+1}-T_{j-1}$ & $\partial^{2} \mathrm{~T}$ & $\mathrm{~T}_{\mathrm{i}, \mathrm{j}+1, \mathrm{l}}-2 \mathrm{~T}_{\mathrm{i}, \mathrm{j}, \mathrm{l}}+\mathrm{T}_{\mathrm{i}, \mathrm{j}-1, \mathrm{l}}$ & $\mathrm{T}_{\mathrm{i}, \mathrm{j}+1, \mathrm{l}}-2 \mathrm{~T}_{\mathrm{i}, \mathrm{j}, \mathrm{l}}+\mathrm{T}_{\mathrm{i}, \mathrm{j}-1, \mathrm{l}}$ \\
\hline$\overline{\partial y}$ & $\overline{y_{j+1}-y_{j-1}}$ & $\overline{\partial y^{2}}$ & $\left(y_{j+1}-y_{j-1}\right)^{2}$ & $\Delta y^{2}$ \\
\hline$\partial \mathrm{T}$ & $\mathrm{T}_{1+1}-\mathrm{T}_{1-1}$ & $\partial^{2} \mathrm{~T}$ & $\mathrm{~T}_{\mathrm{i}, \mathrm{j}, \mathrm{l}+1}-2 \mathrm{~T}_{\mathrm{i}, \mathrm{j}, \mathrm{l}}+\mathrm{T}_{\mathrm{i}, \mathrm{j}, \mathrm{l}-1}$ & $\mathrm{~T}_{\mathrm{i}, \mathrm{j}, \mathrm{l}+1}-2 \mathrm{~T}_{\mathrm{i}, \mathrm{j}, \mathrm{l}}+\mathrm{T}_{\mathrm{i}, \mathrm{j}, \mathrm{l}-1}$ \\
\hline$\overline{\partial z}$ & $\overline{z_{l+1}-z_{l-1}}$ & $\overline{\partial \mathrm{z}^{2}}$ & $\left(\mathrm{z}_{1+1}-\mathrm{z}_{1-1}\right)^{2}$ & $\Delta \mathrm{z}^{2}$ \\
\hline
\end{tabular}

In the transient case there will be at least one time derivative. According to [5], the term $\frac{\partial \mathrm{T}}{\partial \mathrm{t}}$, with time increments $(\kappa)$, is defined as:

$$
\frac{\partial \mathrm{T}}{\partial \mathrm{t}}=\frac{T_{i}^{k+1}-T_{i}^{k}}{\Delta t}
$$

By replacing the ODEs with the corresponding differences in Eq. (1), we define the general heat conduction equation in three-dimensional finite differences:

$$
\begin{aligned}
& \frac{T^{k}{ }_{i+1, j, l}-2 T^{k}{ }_{i}+T^{k}{ }_{i-1}, j, l}{\Delta x^{2}}+\frac{T^{k}{ }_{i, j+1, l}-2 T^{k}{ }_{i}+T^{k}{ }_{i, j-1, l}}{\Delta y^{2}}+\frac{T^{k}{ }_{i, j, l+1}-2 T^{k}{ }_{i}+T^{k}{ }_{i, j, l-1}}{\Delta z^{2}}+\frac{q^{k}}{k} \\
& =\frac{1}{D} \frac{T_{i}^{k+1}-T_{i}^{k}}{\Delta t}
\end{aligned}
$$

Beign $D=\frac{k}{\rho c}$, known as termal diffusivity. 
Considering $\Delta x^{2}=\Delta y^{2}=\Delta z^{2}$, and simplifying Eq. (3), arise the Eq. (4):

$$
\begin{gathered}
T_{i}^{k+1}=F\left(T_{i+1, j, l}^{k}+T^{k}{ }_{i-1}, j, l+T^{k}{ }_{i, j+1, l}+T^{k}{ }_{i, j-1, l}+T^{k}{ }_{i, j, l+1}+T^{k}{ }_{i, j, l-1}\right)+(1-6 F) T_{i}{ }^{k} \\
+G
\end{gathered}
$$

In which,

$$
\begin{gathered}
F=\frac{\Delta t \cdot D}{\Delta x^{2}} \\
G=\frac{q^{k} \cdot \Delta x^{2} \cdot \Delta t}{\rho c}
\end{gathered}
$$

The expression in FDM allows the calculation of temperature at any point in the domain. The virtual points outside the domain are determined by the boundary conditions. The application of the FDM expression to all points of the domain leads to a system of $\mathrm{n}$ equations with $n$ unknowns, of type $A x=B$, which is solved by the classical mathematical methods in MatLab. [5].

\subsection{General Heat Conduction Equation by Finite Elements Method (FEM):}

According to [5], the temperature distribution $\mathrm{T}(\mathrm{x}, \mathrm{y}, \mathrm{z}, \mathrm{t})$ inside the solid body is defined as:

$$
I=\frac{1}{2} \iiint_{V}\left\lfloor K\left(\left(\frac{\partial \mathrm{T}}{\partial \mathrm{x}}\right)^{2}+\left(\frac{\partial \mathrm{T}}{\partial \mathrm{y}}\right)^{2}+\left(\frac{\partial \mathrm{T}}{\partial \mathrm{z}}\right)^{2}\right)-2\left(\dot{q}-\rho \mathrm{c} \frac{\partial \mathrm{T}}{\partial \mathrm{t}}\right) T\right\rfloor d V
$$

Using Galerkin's Method as solution to Eq. (7), the following steps were adopted, [19]:

1. Divide the domain $\mathrm{V}$ into $\mathrm{E}$ finite elements with $\mathrm{p}$ nodes;

2. Assume the appropriate variational form of $\mathrm{T}$ in finite elements with $e$ elements, expressed by:

$$
T^{(e)}(x, y, z, t)=[N(x, y, z)] \vec{T}^{(e)}
$$

Where,

$$
\begin{aligned}
& {[N(x, y, z)]=\left[\begin{array}{llll}
N_{1}(x, y, z) & N_{2}(x, y, z) & \ldots & N_{p}(x, y, z)
\end{array}\right]} \\
& \overrightarrow{\mathrm{T}}(\mathrm{e})=\left[\begin{array}{c}
\mathrm{T}_{1}(\mathrm{t}) \\
\vdots \\
\mathrm{T}_{2}(\mathrm{t})
\end{array}\right]
\end{aligned}
$$

3. The integral of the weighted residue on the element domain is set equal to zero, having the same weights as the interpolation functions $\mathrm{N}_{\mathrm{i}}$. If the solution of the previous equation is not exact, it is replaced by the differential equation, which instead of zero will have a different value called the residual. Thus, the criterion to be satisfied at each instant of time is:

$$
\mathrm{I}=\iiint_{\mathrm{V}^{\mathrm{e}}}\left[\mathrm{N}_{\mathrm{i}}\left(\mathrm{k}\left(\frac{\partial}{\partial \mathrm{x}}\left(\frac{\partial \mathrm{T}^{(\mathrm{e})}}{\partial \mathrm{x}}\right)+\frac{\partial}{\partial \mathrm{y}}\left(\frac{\partial \mathrm{T}^{(\mathrm{e})}}{\partial \mathrm{y}}\right)+\frac{\partial}{\partial \mathrm{z}}\left(\frac{\partial \mathrm{T}^{(\mathrm{e})}}{\partial \mathrm{z}}\right)\right)\right)+\dot{\mathrm{q}}-\rho \mathrm{c} \frac{\partial \mathrm{T}^{(\mathrm{e})}}{\partial \mathrm{t}}\right] \mathrm{dV}
$$


Rewritng the first termo of the integral:

$$
\iiint_{\mathrm{V}^{\mathrm{e}}} \mathrm{N}_{\mathrm{i}} \mathrm{k} \frac{\partial}{\partial \mathrm{x}}\left(\frac{\partial \mathrm{T}^{(\mathrm{e})}}{\partial \mathrm{x}}\right) \mathrm{dV}=-\iiint_{\mathrm{V}^{\mathrm{e}}} \mathrm{k} \frac{\partial \mathrm{N}_{\mathrm{i}}}{\partial \mathrm{x}}\left(\frac{\partial \mathrm{T}^{(\mathrm{e})}}{\partial \mathrm{x}}\right) \mathrm{dV}+\iiint_{\mathrm{V}^{\mathrm{e}}} \mathrm{N}_{\mathrm{i}} \mathrm{k}\left(\frac{\partial \mathrm{T}^{(\mathrm{e})}}{\partial \mathrm{x}}\right) \mathrm{l}_{\mathrm{x}} \mathrm{dS}
$$

Being $l x$ the cosine in $\mathrm{x}$-direction. For the complete equation:

$$
\begin{gathered}
-\iiint_{\mathrm{V}^{\mathrm{e}}} \mathrm{k}\left[\frac{\partial \mathrm{N}_{\mathrm{i}}}{\partial \mathrm{x}}\left(\frac{\partial \mathrm{T}^{(\mathrm{e})}}{\partial \mathrm{x}}\right)+\frac{\partial \mathrm{N}_{\mathrm{i}}}{\partial \mathrm{y}}\left(\frac{\partial \mathrm{T}^{(\mathrm{e})}}{\partial \mathrm{y}}\right)+\frac{\partial \mathrm{N}_{\mathrm{i}}}{\partial \mathrm{z}}\left(\frac{\partial \mathrm{T}^{(\mathrm{e})}}{\partial \mathrm{z}}\right)\right] \mathrm{dV}+\iiint_{\mathrm{V}^{\mathrm{e}}} \mathrm{N}_{\mathrm{i}} \mathrm{k}\left[\left(\frac{\partial \mathrm{T}^{(\mathrm{e})}}{\partial \mathrm{x}}\right) \mathrm{l}_{\mathrm{x}}+\left(\frac{\partial \mathrm{T}^{(\mathrm{e})}}{\partial \mathrm{y}}\right) \mathrm{l}_{\mathrm{y}}+\right. \\
\left.\left(\frac{\partial \mathrm{T}^{(\mathrm{e})}}{\partial \mathrm{z}}\right) \mathrm{l}_{\mathrm{z}}\right] \mathrm{d} \mathrm{S}+\iiint_{\mathrm{V}_{\mathrm{e}}} \mathrm{N}_{\mathrm{i}} \mathrm{k}\left(\dot{\mathrm{q}}-\rho \mathrm{c} \frac{\partial \mathrm{T}^{(\mathrm{e})}}{\partial \mathrm{t}}\right) \mathrm{dV}
\end{gathered}
$$

The boundary of element ${ }^{(e)}$ is composed of $S 1^{(e)}, S 2^{(e)}$ and $S 3^{(e)}$. The surface integral equals to zero due to $T 0$ in $S 1^{(e)}$, the derivatives of $T^{(e)}$ in respect to $\mathrm{x}, \mathrm{y}$ and $\mathrm{z}$ are zero too. In $S 2^{(e)}$ and $S 3^{(e)}$, the boundary conditions satisfies the problem, thus having as surface integral in $S 2^{(e)}$ and $S 3^{(e)}$ :

$$
\begin{aligned}
& \iint_{S_{2}(e)_{+} S_{3}(e)} N_{i} k\left[\left(\frac{\partial T^{(e)}}{\partial x}\right) l_{x}+\left(\frac{\partial T^{(e)}}{\partial y}\right) l_{y}+\left(\frac{\partial T^{(e)}}{\partial z}\right) l_{z}\right] d S \\
= & \iint_{S_{2}(e)}^{(e)} N_{i} q d S_{2}-\iint_{S_{2}(e)} h\left(T^{(e)}-T_{\infty}\right) d S_{3}
\end{aligned}
$$

The matricial form of the equation is:

$$
\left[\mathrm{K}_{1}{ }^{(\mathrm{e})}\right] \overrightarrow{\mathrm{T}}^{(\mathrm{e})}+\left[\mathrm{K}_{2}{ }^{(\mathrm{e})}\right] \overrightarrow{\mathrm{T}}^{(\mathrm{e})}+\left[\mathrm{K}_{3}{ }^{(\mathrm{e})}\right] \overrightarrow{\mathrm{T}}^{(\mathrm{e})}-\overrightarrow{\mathrm{P}}^{(\mathrm{e})}=\overrightarrow{0}
$$

In which:

$$
\begin{gathered}
\boldsymbol{K}_{1 i j}{ }^{(e)}=-\iiint_{V^{e}} k\left[\frac{\partial N_{i}}{\partial \mathrm{x}}\left(\frac{\partial \mathrm{T} N_{j}}{\partial \mathrm{x}}\right)+\frac{\partial N_{i}}{\partial \mathrm{y}}\left(\frac{\partial \mathrm{T} N_{j}}{\partial \mathrm{y}}\right)+\frac{\partial N_{i}}{\partial \mathrm{z}}\left(\frac{\partial \mathrm{T} N_{j}}{\partial \mathrm{z}}\right)\right] d V \\
\boldsymbol{K}_{2 i j}{ }^{(e)}=\iint_{S_{3}(e)} h N_{i} N_{j} d S_{3} \\
\boldsymbol{K}_{3 i j}{ }^{(e)}=\iint_{V^{(e)}} \rho c N_{i} N_{j} d V \\
\vec{P}^{(e)}{ }_{i}=\iint_{V^{(e)}} \dot{q} N_{i} d V-\iint_{S_{2}(e)} N_{i} q d S_{2}-\iint_{S_{2}(e)} h\left(T_{\infty}\right) d S_{3}
\end{gathered}
$$

4. The matrix elements can be written in the usual form:

$$
\begin{gathered}
{\left[\underline{K}_{3}\right] \underline{\vec{T}(e)}+\left[\underline{K}^{(e)}\right] \underline{\vec{T}}^{(e)}=\underline{\vec{P}}} \\
{\left[\underline{K}_{3}\right]=\sum_{e=1}^{E}\left[K_{3}{ }^{(e)}\right]} \\
{[\underline{K}]=\sum_{e=1}^{E}\left[K_{1}^{(e)}+K_{2}{ }^{(e)}\right]}
\end{gathered}
$$




$$
\underline{\vec{P}}=\sum_{e=1}^{E}\left[\overrightarrow{\boldsymbol{P}}^{(e)}\right]
$$

5. The equations must be solved by incorporating the boundary conditions and the initial conditions. The expressions $\left[\boldsymbol{K}_{1}{ }^{(\boldsymbol{e})}\right],\left[\boldsymbol{K}_{\mathbf{2}}{ }^{(\boldsymbol{e})}\right],\left[\boldsymbol{K}_{\mathbf{3}}{ }^{(\boldsymbol{e})}\right]$ and $\overrightarrow{\boldsymbol{P}}^{(\boldsymbol{e})}$ are written as matrixes with notation:

$$
\begin{aligned}
& \boldsymbol{K}_{\mathbf{1}}{ }^{(e)}=\iiint_{V}[B]^{T}[D][B] d V \\
& \boldsymbol{K}_{\mathbf{2}}{ }^{(e)}=\iiint_{S_{3}} h[N]^{T}\lceil N\rceil d S_{3} \\
& \boldsymbol{K}_{3}{ }^{(e)}=\iiint_{V} \rho c[N]^{T}[N] d V \\
& \vec{P}^{(e)}=\vec{P}_{1}^{(e)}-\vec{P}_{2}^{(e)}+\vec{P}_{3}^{(e)}
\end{aligned}
$$

Where:

$$
\begin{aligned}
& {\overrightarrow{\boldsymbol{P}_{\mathbf{1}}}}^{(\boldsymbol{e})}=\iiint_{V} \dot{\boldsymbol{q}}[N]^{T} d V \\
& {\overrightarrow{\boldsymbol{P}_{\mathbf{2}}}}^{(\boldsymbol{e})}=\iint_{S_{3}(e)} q[N]^{T} d S_{2}
\end{aligned}
$$

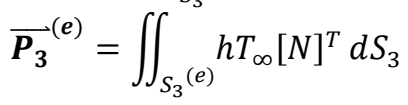

$$
\begin{aligned}
& {[D]=\left[\begin{array}{ccc}
k_{x} & 0 & 0 \\
0 & k_{y} & 0 \\
0 & 0 & k_{z}
\end{array}\right]} \\
& {[B]=\left[\begin{array}{cccc}
\frac{\partial N_{1}}{\partial x} & \frac{\partial N_{2}}{\partial x} & \ldots & \frac{\partial N_{p}}{\partial x} \\
\frac{\partial N_{1}}{\partial y} & \frac{\partial N_{2}}{\partial y} & \ldots & \frac{\partial N_{p}}{\partial y} \\
\frac{\partial N_{1}}{\partial z} & \frac{\partial N_{2}}{\partial z} & \ldots & \frac{\partial N_{p}}{\partial z}
\end{array}\right]}
\end{aligned}
$$




\section{RESULTS}

The presented results were developed by FDM and FEM in the first problem, with implementation in MATLAB and PHYTON, respectively, showing the transient heat flux for a situation with heat generation. In the second problem, results are displayed for a thermomechanical coupling using the analytical solution compared to the FEM using the ANSYS WORKBENCH software.

\subsection{Complete 2D Heat Equation with Internal Heat Generation}

The proposed case consists of a concrete plate of unit dimensions, with internal heat generation. The points analyzed were P1, P2 and P3, which are located in the center line of the $\mathrm{X}$-axis, $0.25 \mathrm{~m}$ from the upper surface, at the plate central point and 0.25 from the lower surface of the y-axis, respectively. The adopted heat generation is represented by $q^{*}=q_{0} \cdot m \cdot \mathrm{e}^{(-m t)}$, where $\mathrm{q}_{0}=200 \mathrm{~J} / \mathrm{m}^{3} \mathrm{~s}$.

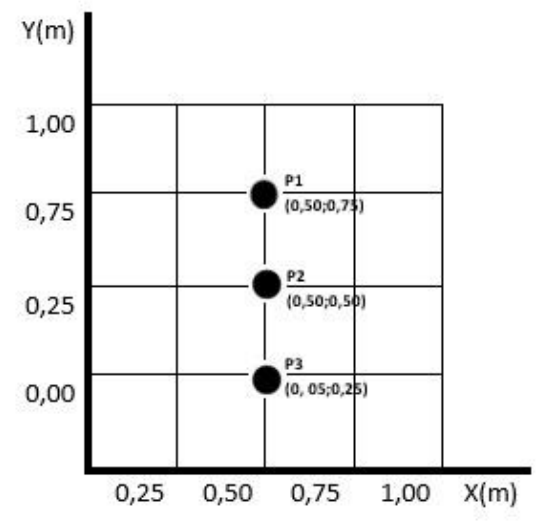

Figure 2: Plate and points analyzed by equaction.

The considered thermal and mechanical properties are in Tab. (2):

Table 2: Thermal and mechanical properties

\begin{tabular}{ccc}
\hline Property & SI & Valor \\
\hline Thermal Conductivity & k & $1,79\left(\mathrm{~W} / \mathrm{m} .{ }^{\circ} \mathrm{C}\right)$ \\
\hline Specific Heat & c & $1000\left(\mathrm{~J} / \mathrm{g} .{ }^{\circ} \mathrm{C}\right)$ \\
\hline Specific Mass & $\rho$ & $2388\left(\mathrm{Kg} / \mathrm{m}^{3}\right)$ \\
\hline Thermal Expansion Coefficient & $\alpha$ & $16,67.10^{-6}\left(/{ }^{\circ} \mathrm{C}\right)$ \\
\hline Elasticity Module & E & $210000 \mathrm{MPa}$ \\
\hline $\begin{array}{c}\text { Conductive Heat Transfer } \\
\text { Coefficient }\end{array}$ & $\mathrm{h}$ & $13,95 \mathrm{~W} / \mathrm{mK}$ \\
\hline
\end{tabular}

\subsubsection{Analysis of Results}

The comparison between results was performed by comparing the temperature evolution curves obtained by the numerical solutions of the FDM and FEM at the stipulated time of 17280 $\mathrm{s}$, as a function of the positions shown in Figs $(3,4)$. The first graph, Fig. $(03)$, considered the position variation only around the $\mathrm{x}$-axis by adopting the central position of the plate $(0.50 \mathrm{~m})$ 
at $\mathrm{y}$. In the abscissa axis the position variations in $\mathrm{x}(\mathrm{m})$ were considered and in the ordinates the temperature variation $\left({ }^{\circ} \mathrm{C}\right)$.

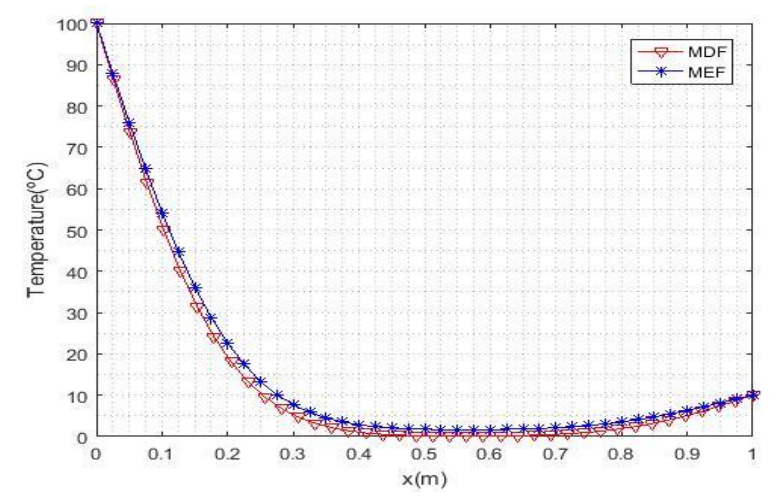

Figure 3: Temperature along the $\mathrm{X}$-axis for the complete 2D equation

Analyzing Fig. (3) it can be seen that in the position $\mathrm{x}=0.00 \mathrm{~m}$ the temperature corresponds to $100^{\circ} \mathrm{C}$, and for position $\mathrm{x}=1.00 \mathrm{~m}$ to $10^{\circ} \mathrm{C}$, which are the initial boundary conditions. In other positions, the results overlap, showing that the results obtained are reliable. The graph in Fig. (4) considered the position variation only around the y-axis and adopted the central position $(0.50 \mathrm{~m})$ for $\mathrm{x}$. In the abscissa axis are the position variations in $\mathrm{y}(\mathrm{m})$ and in the ordinates the temperature variation $\left({ }^{\circ} \mathrm{C}\right)$.

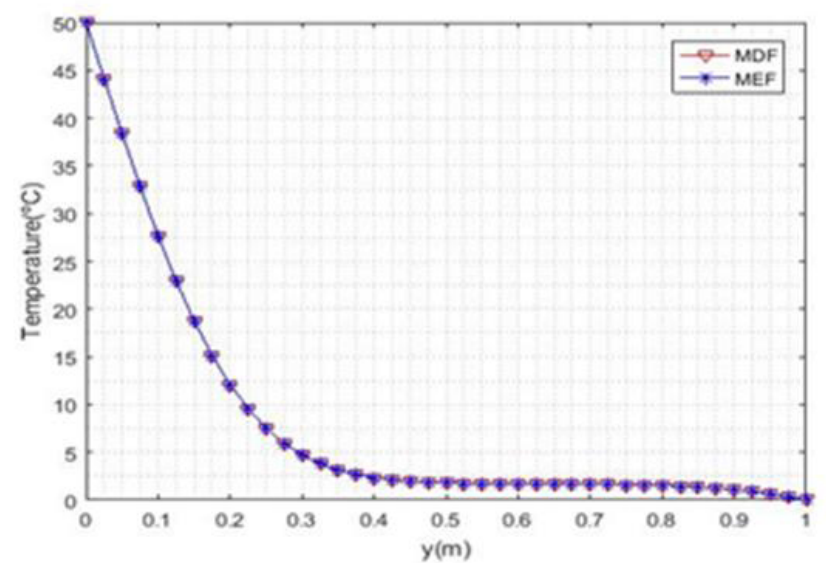

Figure 4: Temperature along the $\mathrm{Y}$-axis for the complete 2D equation

As in the graph of Fig. (3), in Fig. (4), the temperatures dependent on the boundary conditions remained the same, at $50{ }^{\circ} \mathrm{C}$ and $0{ }^{\circ} \mathrm{C}$, and the other points presented overlapping results.

Afterwards, the temperature evolution was analyzed as a function of time by the two numerical methods at three points on the plate (P1, P2 and P3). The point $\mathrm{P} 1$ is located at the coordinates $\mathrm{x}=0.50 \mathrm{~m}$ and $\mathrm{y}=0.25 \mathrm{~m}$. $\mathrm{P} 2$ at coordinates $\mathrm{x}=0.50 \mathrm{~m}$ and $\mathrm{y}=0.50 \mathrm{~m}$ and point $\mathrm{P} 3$ at coordinates $x=0.50 \mathrm{~m}$ and $y=0.75 \mathrm{~m}$. The comparisons can be seen in Figs. (5a), (5b) and 
$(5 c)$.

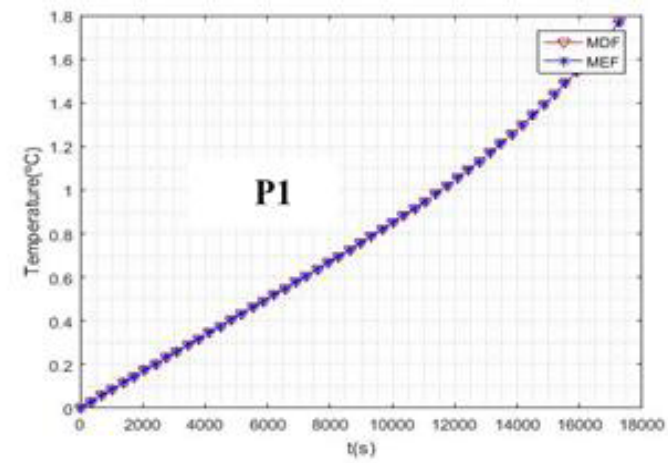

Figure 5.a: Transient temperatura analysis in point P1

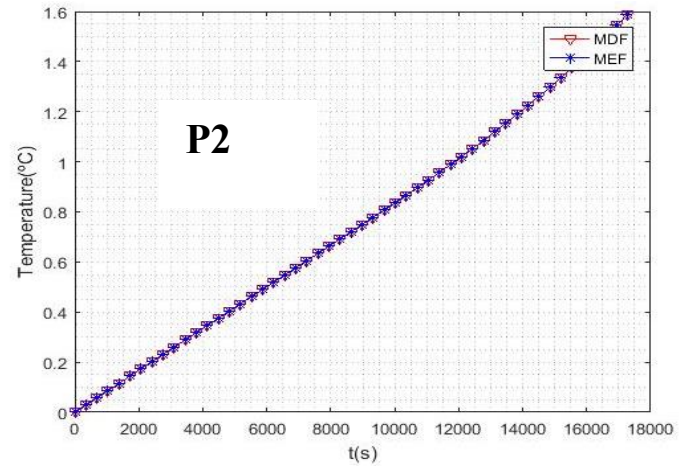

Figure 5.b: Transient temperatura analysis in point P)

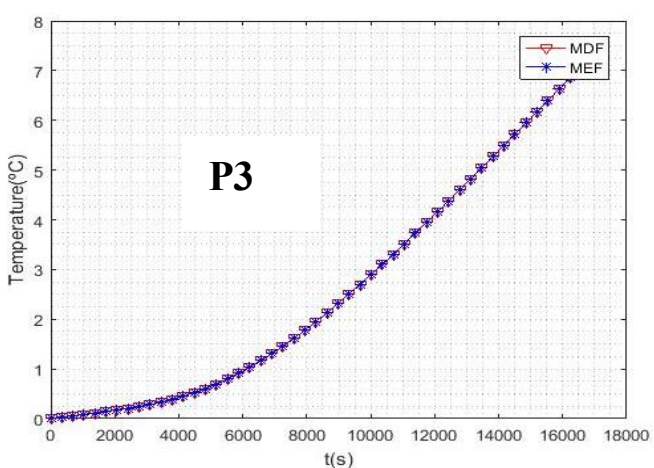

Figure 5.c: Transient temperatura analysis in point P3

In all the graphs of Fig. (5), it can be observed that the results obtained by FDM and FEM are coincident, showing a good treatment of data and that both are efficient in the solution of heat problems.

\subsection{Thermomechanical Coupling in a Retangular Plate}

In this section, numerical-analytical results will be compared for the case of rectangular plate with fixed boundary conditions subject to a non-uniform heat variation $\Delta \mathrm{T}$, according to Fig. (6), as proposed by [20].
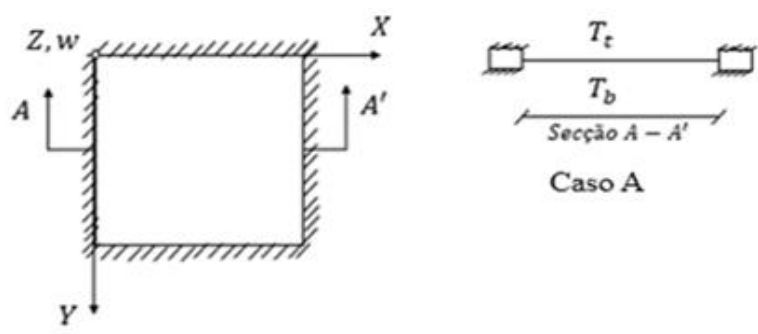

$$
T_{t}>T_{b}
$$

Figure 6: Mechanical results comparison for a bi-crimped beam. 
Considering the edges of the plate free to slide, but with restriction to rotation, case A, the moment in the plate is given by Eq. (33).

$$
\mathrm{M}=-\frac{\mathrm{D} \alpha(\Delta \mathrm{T})}{\mathrm{h}}(1+v)
$$

Being $\mathrm{M}$ the moment due to the temperature gradient $(\boldsymbol{\Delta T}), \boldsymbol{D}=\frac{\boldsymbol{E} \boldsymbol{h}^{3}}{\mathbf{1 2 ( 1 - \boldsymbol { v } ^ { 2 } )}}$ is the flexural stiffness and $\boldsymbol{v}$ is the Poisson's coefficient.

The correspondent maximum stress $\sigma_{\max , b}$ is given by:

$$
\sigma_{\max , b}= \pm \frac{6 M}{h^{2}}
$$

Was modeled in ANSYS Workbench a solid body of dimensions $(\mathrm{x}, \mathrm{y}, \mathrm{z})=(0.5,0.5,0.1)$, as in Fig. (XX), with temperatures $\mathrm{T}=0{ }^{\circ} \mathrm{C}$ at $\mathrm{z}=0.0 \mathrm{~m}$ and $\mathrm{T}=100{ }^{\circ} \mathrm{C}$ at $\mathrm{z}=0.1 \mathrm{~m}$. The results for the temperatures can be visualized in Fig. (XX), presenting a uniform thermal distribution.

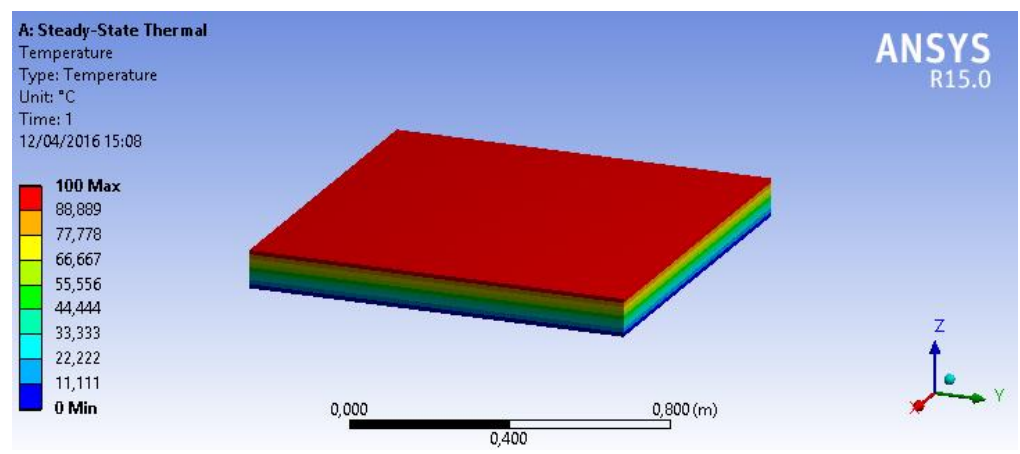

Figura 07: Resultados mecânicos para a viga biengastada

If there is only the displacement restriction at $\mathrm{z}$, the maximum and minimum stresses found at the central points of the body are $\pm 9.4303 \mathrm{E} 7 \mathrm{~Pa}$. Using Eqs. (33) and (34), the maximum stresses are $\pm 8.57 \mathrm{E} 7 \mathrm{~Pa}$, differing only in $9.0 \%$ from the software result. The graph of Fig. (08) presents the stress distribution in the abscissa axis $(\mathrm{Pa})$, by the thickness in the ordinates axis (m). The 'calculated stress' curve represents the maximum tensions found analytically, 'Stress $\mathrm{X}$ ' represents the stresses found by the program along the width and 'Stress $Z$ ' the stresses in the thickness direction, being free to rotate, the stresses in that axis are zero. However, the maximum stresses by both methods are very close.

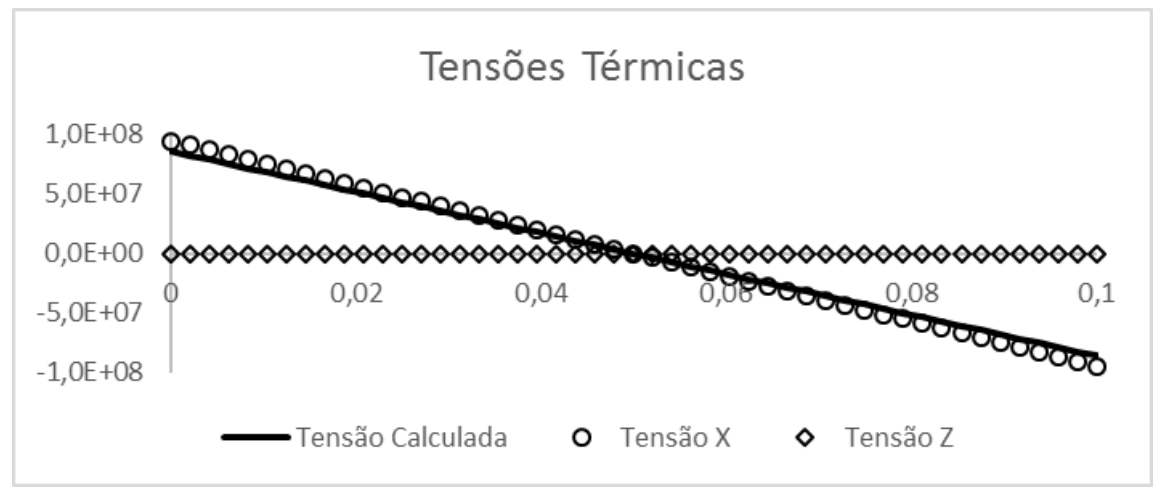

Figure 08: Thermal stresses result comparison for different cases 
With this analysis, it can be affirmed that the analytical method and the MEF, applied through the ANSYS, can be used in the resolution of thermomechanical problems in engineering, and can later apply this methodology to more complex situations. Other similar analyzes can be observed in [9].

\section{CONCLUSIONS}

With the presented results, it is possible to affirm that the thermal and thermomechanical analyzes can be done by means of different methods, like the analytical method, FDM and FEM. The comparisons between the simulations performed with the exposed alternatives were coincident, showing a good treatment of the data and a correct manipulation of the computational tools. It is also noted that the initial conditions and boundary properly applied are essential in order to reach the expected results. Although the cases presented are simple, they are essential if advances are to be achieved, as they are part of a needed preliminary study phase of validation that aims to arrive at solutions, with confidence in numerical simulations, of more complex problems.

\section{ACKNOWLEDGMENT}

The author thanks UnB, PECC-UnB and FAPDF for their support in the development of this research and my supervisor of scientific initiation Prof. Dr. Lineu José Pedroso, who directed, dedicated time and unconditionally encouraged the accomplishment of this work.

\section{REFERENCES}

[1] Incropera, F.P.; Dewitt, D.P. Fundamentos de Transferência de Calor e de Massa, 3a Edição, LTC S. A., R. J. 1990.

[2] Hoffman, J. D., 2001. Numerical methods for engineers and scientists, Marcel Dekker, Inc.

[3] Corrêa, L.; Lima, G. A. B.; Ferreira, V. G. Solução Numérica de Equações Diferenciais Parciais via o Método das Diferenças Finitas. II Colóquio de Matemática do Centro Oeste. 2011.

[4] Becker, E., 1981. Finite elements. Englewood Cliffs, N.J: Prentice-Hall

[5] Coelho, N. A.. Métodos Analíticos e Numéricos para o Estudo dos Efeitos Termomecânicos no Concreto Massa Orientados às Barragens de Gravidade. Tese de Doutorado. Universidade de Brasília - UnB. Brasília: 2016.

[6] Almeida, G. V.; Coelho, N. A.; Pedroso, L. J.. Distribuição de temperatura em placas em regime transiente: comparação entre solução analítica e numérica. In:XXXVII Iberian Latin American Congress on Computational Methods in Engineering. Brasília: 2016.

[7] Coelho, N. A.. Um Estudo Numérico do Efeito Térmico em Concreto Massa. Dissertação de Mestrado. Universidade de Brasília - UnB. Brasília: 2012

[8] Coelho, N. A.; Gomes, F. M. P.; Pedroso, L. J.; Silva, D. A.. Um estudo comparativo analítico-numérico de tensões térmicas em casos clássicos de vigas e placas. In: XXXVII Iberian Latin American Congress on Computational Methods in Engineering. Brasília: 2016 
[9] Coelho, N. A.; Silva, D. A.; Pedroso, L. J.; Efeito térmico provocado pelo calor de hidratação em barragem de gravidade construída em camadas. In: XXXVII Iberian Latin American Congress on Computational Methods in Engineering. Brasília: 2016b.

[10] Coelho, N. A.; Pedroso, L. J. Estudo da Equação de Calor em Elemento Uni, Bi e Tridimensional. Relatório Técnico - RTP. Universidade de Brasília - UnB. Brasília: 2013.

[11] Gomes, F. M. P.; Coelho, N. A.; Pedroso, L. J.. Uma solução analítico-numérica para a difusividade do calor em um cilindro com e sem geração de calor. In: XXXVII Iberian Latin American Congress on Computational Methods in Engineering. Brasília: 2016.

[12] Gomes, F. M. P.; Concreto nas primeiras idades: propriedades e modelagem termomecânica simplificada. Dissertação de Mestrado. Universidade Federal de Goiás. Goiânia: 2011.

[13] Pedroso, L. J. Manuscritos, esquemas, discussões e notas de seções de orientações, 20132016. In: Programa de Pós-Graduação em Estruturas e Construção Civil - PECC, Universidade de Brasília, Brasilia, 2016.

[14] Pedroso, L. J.. Método das Diferenças Finitas em Vigas Esbeltas. Apostilha didática. In: Programa de Pós-Graduação em Estruturas e Construção Civil - PECC, Universidade de Brasília, Brasilia, 2005.

[15] Pedroso, L.J.. Método das Diferenças Finitas. In: Notas de Curso e Apostila Didática, UnB-FT/ENC, Vs.3 - Brasília, DF, 2003.

[16] Pedroso, J. L.. Barragens de Concreto: Aspectos Gerais e Fundamentos do Cálculo de Tensões e da Estabilidade Baseado no Método de Gravidade. Apostila do Curso de Barragens de Concreto. Universidade de Brasília - UnB, Brasília, 2002.

[17] Pedroso,L. J., 2011. Uma Introdução do Método das Diferenças Finitas Centrais em Cavidades Acústicas 2D. Publicação Didática, Universidade de Brasília.

[18] Çengel, Y. A. 2006. Heat and Mass Transfer: A Practical Approach, 3ª Ed., McGrawHill, Singapore.

[19] Rao, S. S.; The Finite Element Method in Engineering. $3^{\text {a }}$ ed. United States of America: Butterworth Heinemann: 1999.

[20] SZILARD, R.. Theory and Analysis of Plates: Classical and Numerical Methods. John Wiley \& Sons. New Jersey: 2004. 